\title{
Adiponectin in relation to childhood myeloblastic leukaemia
}

\author{
E Petridou*,1,2, CS Mantzoros ${ }^{3}$, N Dessypris', SK Dikalioti', D Trichopoulos ${ }^{1,2}$ and the Childhood Hematology \\ Oncology Group
}

'Department of Hygiene and Epidemiology, Athens University Medical School, 75 Mikras Asias Str, Goudi, Athens II 527, Greece; ${ }^{2}$ Department of Epidemiology, Harvard School of Public Health, Boston, MA 0211 5, USA; ${ }^{3}$ Division of Endocrinology, Diabetes and Metabolism, Department of Internal Medicine, Beth Israel Deaconess Medical Center, Harvard Medical School, Boston, MA, USA

Adiponectin, an adipocyte-specific secretory protein known to induce apoptosis, has been reported to be inversely related to breast and endometrial cancers and recently found to inhibit proliferation of myeloid but not lymphoid cell lines. We hypothesised that adiponectin may be inversely associated with acute myeloblastic leukaemia (AML), but not with acute lymphoblastic leukaemia of $B$ (ALL-B) or T (ALL-T) cell origin in children. Blood samples and clinical information were collected over the period 1996-2000 from 201 children (0-14 years old) with leukaemia (22 AML, I6I ALL-B and I 8 ALL-T cases) through a national network of childhood Hematology-Oncology units in Greece and from 201 controls hospitalised for minor pediatric ailments. Serum adiponectin levels were measured under code, at the Beth Israel Deaconess Medical Center, Boston, MA, USA using a radioimmunoassay procedure. Each of the three leukaemia groups was compared with the control group through multiple logistic regression. Odds ratios (OR) and 95\% confidence intervals $(95 \% \mathrm{Cl}$ ) for an increase of adiponectin equal to I s.d. among controls were estimated controlling for gender, age, as well as for height and weight, expressed in age-gender-specific centiles of Greek growth curves. Adiponectin was inversely associated with $\mathrm{AML}(\mathrm{OR}=0.56 ; 95 \% \mathrm{Cl}, 0.34-0.94)$, whereas it was not significantly associated with either $\mathrm{ALL}-\mathrm{B}$ $(\mathrm{OR}=0.88 ; 95 \% \mathrm{Cl}, 0.7 \mathrm{I}-\mathrm{I} .10)$ or $\mathrm{ALL}-\mathrm{T}(\mathrm{OR}=1.08 ; 95 \% \mathrm{Cl}, 0.67-1.72)$. Biological plausibility and empirical evidence point to the importance of this hormone in the pathogenesis of childhood AML.

British Journal of Cancer (2006) 94, I56- 160. doi: I0.1038/sj.bjc.6602896 www.bjcancer.com

(c) 2006 Cancer Research UK

Keywords: adiponectin; childhood; leukaemia

With the exception of ionizing radiation and genetic abnormalities, the aetiology of childhood leukaemia has not yet been fully elucidated. It also remains unknown whether the principal forms of childhood leukaemia, namely acute lymphoblastic leukaemia of B-cell origin (ALL-B), acute lymphoblastic leukaemia of T-cell origin (ALL-T) and acute myeloblastic leukaemia (AML) have similar aetiologies and/or pathogenesis. Most aetiologic research on childhood leukaemia has focused on ALL due to its much higher frequency in comparison to that of AML (Petridou and Trichopoulos, 2002; McNally and Eden, 2004; Randolph, 2004).

Adiponectin is an adipocyte-secreted hormone which has been found to induce apoptosis and suppress angiogenesis (Cao et al, 1999; Brakenhielm et al, 2004). This hormone has also been inversely associated with both adult forms of cancer that have been epidemiologically investigated, namely breast cancer (Miyoshi et al, 2003; Mantzoros et al, 2004b) and endometrial cancer (Petridou et al, 2003; Dal Maso et al, 2004). In a recent in vitro study Yokota et al have investigated the functions of adiponectin in haematopoiesis and found that adiponectin predominantly inhibits proliferation of myeloid cell lines, and induces apoptosis in myelomonocytic leukaemia lines, but did not suppress

* Correspondence: Dr E Petridou, Professor of Preventive Medicine and Epidemiology; E-mail: epetrid@med.uoa.gr

The Childhood Hematology Oncology Group See Appendix A

Received 15 September 2005; revised 4 November 2005; accepted 4 November 2005 proliferation of erythroid or lymphoid cell lines. We have thus hypothesised that adiponectin might be inversely associated with AML, but not with ALL. We have evaluated this hypothesis by studying 201 children with incident leukaemia and 201 appropriate control children enrolled by a nation-wide network of Pediatric Hematology-Oncology Departments in Greece.

\section{MATERIALS AND METHODS}

A national network comprising all six Childhood HematologyOncology Departments operating in Greece has been established and has coordinated epidemiological research for the last 15 years (Petridou et al, 1993, 1996). In the present study, we have included childhood leukaemia cases (0-14 years old) first diagnosed in Greece during a 5-year period (1996-2000). Children from one of the two Departments in Thessaloniki, however, were not included for administrative reasons. Thus, the study was based on 281 cases of childhood leukaemia diagnosed in five Departments, three in Athens, one in Thessaloniki and one in Crete. Of these cases, 80 were not included, because informed consent could not be obtained before the onset of therapy or laboratory samples were inappropriate or inadequate. These exclusions are unlikely to have introduced selection bias because it was based on technical and administrative reasons. Moreover, serum ADP levels could not impact on patients' decisions to participate in our study; thus it is not possible to have any influence on the reported results. Of the remaining 201 cases of childhood leukaemia, 161 were of B-cell 
origin (ALL-B), 18 of T-cell origin (ALL-T) and 22 had AML. We have not included in the present study cases with Down's syndrome, Fanconi anaemia, other predisposing to leukaemia genetic conditions and children with leukaemia as a second cancer or cases with a previous history of myelodysplasia.

For each child with leukaemia, a control child of the same gender and similar age ( \pm 6 months) was sought among those concurrently admitted to the Pediatric Departments of the same Hospitals for minor pediatric ailments. For only 11 of them the parents were unable or unwilling to provide informed consent and these were properly substituted. Among the 201 controls, 88 were admitted for mild respiratory conditions, viral infections or allergy (bronchitis, asthma, urticaria), 35 for gastrointestinal or genitourinary conditions (gastroenteritis, abdominal pain, urinary tract infections), 31 for nervous system conditions (febrile seizures, transient loss of consciousness, dizziness, headache), 21 for injuries including acute poisoning and near drowning, six for muscle-osteoarticular conditions (arthritis, joint pain) and 20 for other conditions and malformations (chest pain, paleness, double urethra).

Informed consent was obtained by the guardians of all children and the study protocol was approved by the Ethics Committee of the University of Athens Medical School. The parents of all cases and controls were interviewed in the hospital wards, in most instances by the same interviewer. The child's height and weight were abstracted from the medical records and transformed into age-gender-specific centiles, to allow comparisons across different ages, using growth curves developed for Greek children by the First Department of Pediatrics of the Athens Medical School (Chiotis et al, 2003). Information on the type of leukaemia was abstracted from the medical records and blood samples were collected during routine clinical procedures before the initiation of therapy.

All coded samples were centrifuged and frozen sera were sent in dry ice to the coordinating centre in Athens where they were stored at $-70^{\circ} \mathrm{C}$ prior to being air shipped in one batch to the Beth Israel Deaconess Medical Center, in Boston, USA. Blinded adiponectin measurements were performed by a radioimmunoassay procedure with a sensitivity of $2 \mathrm{ng} \mathrm{ml}^{-1}$, and intra-assay coefficient of variation of $<10 \%$ as previously described (Petridou et al, 2003; Dal Maso et al, 2004; Mantzoros et al, 2004b). Average preservation time was similar for cases and controls, and adiponectin levels do not systematically change with storage time.

Initially cases of childhood leukaemia, by type of disease, as well as control children were classified by gender, age and age-genderspecific centiles of height and weight. Representative values of adiponectin, by disease status, were subsequently calculated. In order to study a possible association of adiponectin with any of the three different types of childhood leukaemia, we modelled the data through multiple logistic regression in three distinct models using case/control status as the outcome variable and adiponectin (in increments of one s.d. of the hormone among controls) as well as gender, age and age-gender-specific centiles of height and weight as predictor variables. We have opted for unconditional logistic regression in order to utilise the adiponectin data from all variable controls in the crucial analysis concerning AML cases. Adjustment for covariates chosen as possible predictors of either adiponectin levels or disease risk (e.g. maternal smoking during pregnancy) and, thus, as conceivable confounders of the association of adiponectin levels and childhood leukaemia, have not altered the results appreciably (data not shown). The SAS statistical package was used in all analyses (SAS Institute Inc., 1989).

\section{RESULTS}

Table 1 shows the distribution of 201 children with childhood leukaemia by disease type and 201 controls by gender, age and
Table I Distribution of 201 children with leukaemia by type and 201 control children by gender age and age-gender-specific centiles of height and weight

\begin{tabular}{|c|c|c|c|c|c|c|c|c|}
\hline \multirow[b]{2}{*}{ Variable } & \multicolumn{2}{|c|}{ ALL-B } & \multicolumn{2}{|c|}{ ALL-T } & \multicolumn{2}{|c|}{ AML } & \multicolumn{2}{|c|}{ Controls } \\
\hline & $\mathbf{N}$ & $\%$ & $\mathbf{N}$ & $\%$ & $\mathbf{N}$ & $\%$ & $\mathbf{N}$ & $\%$ \\
\hline \multicolumn{9}{|l|}{ Gender } \\
\hline Male & 77 & 47.8 & 13 & 72.2 & 10 & 45.5 & 100 & 49.8 \\
\hline Female & 84 & 52.2 & 5 & 27.8 & 12 & 54.5 & 101 & 50.2 \\
\hline$P$-value (vs controls; $\chi^{2} \mid d f$ ) & \multicolumn{2}{|c|}{0.71} & \multicolumn{2}{|c|}{0.07} & \multicolumn{2}{|c|}{0.70} & & \\
\hline \multicolumn{9}{|l|}{ Age (years) } \\
\hline$<1$ & 2 & 1.2 & 0 & 0.0 & 3 & 13.6 & 4 & 2.0 \\
\hline $\mid-4$ & 90 & 55.9 & 6 & 33.3 & 12 & 54.6 & 108 & 53.7 \\
\hline $5-9$ & 48 & 29.8 & 8 & 44.5 & 2 & 9.1 & 60 & 29.9 \\
\hline $10+$ & 21 & 13.1 & 4 & 22.2 & 5 & 22.7 & 29 & 14.4 \\
\hline P-value for trend (vs controls; $\chi^{2} 3 \mathrm{df}$ ) & \multicolumn{2}{|c|}{0.92} & \multicolumn{2}{|c|}{0.32} & \multicolumn{2}{|c|}{0.01} & & \\
\hline \multicolumn{9}{|l|}{ Height (age-gender-specific centiles) } \\
\hline$<3$ & 5 & 3.1 & 0 & 0.0 & । & 4.6 & 5 & 2.5 \\
\hline $3-24$ & 23 & 14.3 & 3 & 16.7 & 2 & 9.1 & 26 & 12.9 \\
\hline $25-49$ & 24 & 14.9 & 3 & 16.7 & 0 & 0.0 & 30 & 14.9 \\
\hline $50-74$ & 34 & 21.1 & 3 & 16.7 & 6 & 27.2 & 37 & 18.4 \\
\hline $75-96$ & 54 & 33.5 & 7 & 38.8 & 10 & 45.5 & 70 & 34.9 \\
\hline $97+$ & 20 & 13.1 & 2 & 11.1 & 3 & 13.6 & 33 & 16.4 \\
\hline$P$-value for trend (vs controls; $\left.\chi^{2} \mid d f\right)$ & \multicolumn{2}{|c|}{0.38} & \multicolumn{2}{|c|}{0.80} & \multicolumn{2}{|c|}{0.48} & & \\
\hline \multicolumn{9}{|l|}{ Weight (age-gender-specific centiles) } \\
\hline$<3$ & 2 & 1.3 & । & 5.6 & । & 4.6 & 5 & 2.5 \\
\hline $3-24$ & 25 & 15.5 & 5 & 27.8 & 62 & 27.2 & 26 & 12.9 \\
\hline $25-49$ & 38 & 23.6 & 2 & 11.1 & 52 & 22.7 & 37 & 18.4 \\
\hline $50-74$ & 42 & 26.1 & 3 & 16.6 & 4 & 18.2 & 48 & 23.9 \\
\hline $75-96$ & 44 & 27.3 & 6 & 33.3 & 4 & 18.2 & 66 & 32.8 \\
\hline $97+$ & 10 & 6.2 & । & 5.6 & 2 & 9.1 & 19 & 9.5 \\
\hline$P$-value for trend (vs controls; $\left.\chi^{2} \mid d f\right)$ & \multicolumn{2}{|c|}{0.16} & \multicolumn{2}{|c|}{0.22} & \multicolumn{2}{|c|}{0.06} & & \\
\hline
\end{tabular}

Table 2 Representative values of adiponectin by type of leukaemia and controls

\begin{tabular}{lcccc}
\hline Adiponectin $\left(\boldsymbol{\mu} \mathbf{g ~ m}^{-\mathbf{1}}\right)$ & ALL-B & ALL-T & AML & Controls \\
\hline Number & 161 & 18 & 22 & 201 \\
Median & 17.7 & 16.8 & 14.8 & 19.2 \\
Mean & 18.6 & 19.4 & 15.8 & 19.4 \\
s.d. & 7.8 & 10.6 & 7.4 & 7.9 \\
P-value & 0.33 & 0.96 & 0.048 & \\
\hline
\end{tabular}

$P$-value derived from $t$-tests, comparing means between leukaemia types and controls.

age-gender-specific centiles of height and weight. Since the gender and age matching was carried out for leukaemia cases overall differences in the distribution between controls and cases of the more rare forms of childhood leukaemia are evident. In the main analyses, however, gender and age were adjusted for, categorically, through unconditional logistic regression. Although there were no apparent differences with respect to height and weight, these factors were also adjusted for, as ordered variables, in the main analyses. In the multiple logistic regression analysis, age was also considered as continuous variable and no change was noted.

Table 2 shows representative values of adiponectin among children by different types of leukaemia and among control children. Adiponectin is approximately normally distributed and 
Table 3 Multiple logistic regression-derived, adjusted odds ratios (OR) and $95 \%$ confidence intervals $(95 \% \mathrm{Cl}$ ) for different types of childhood leukaemia by anthropometric variables and adiponectin levels

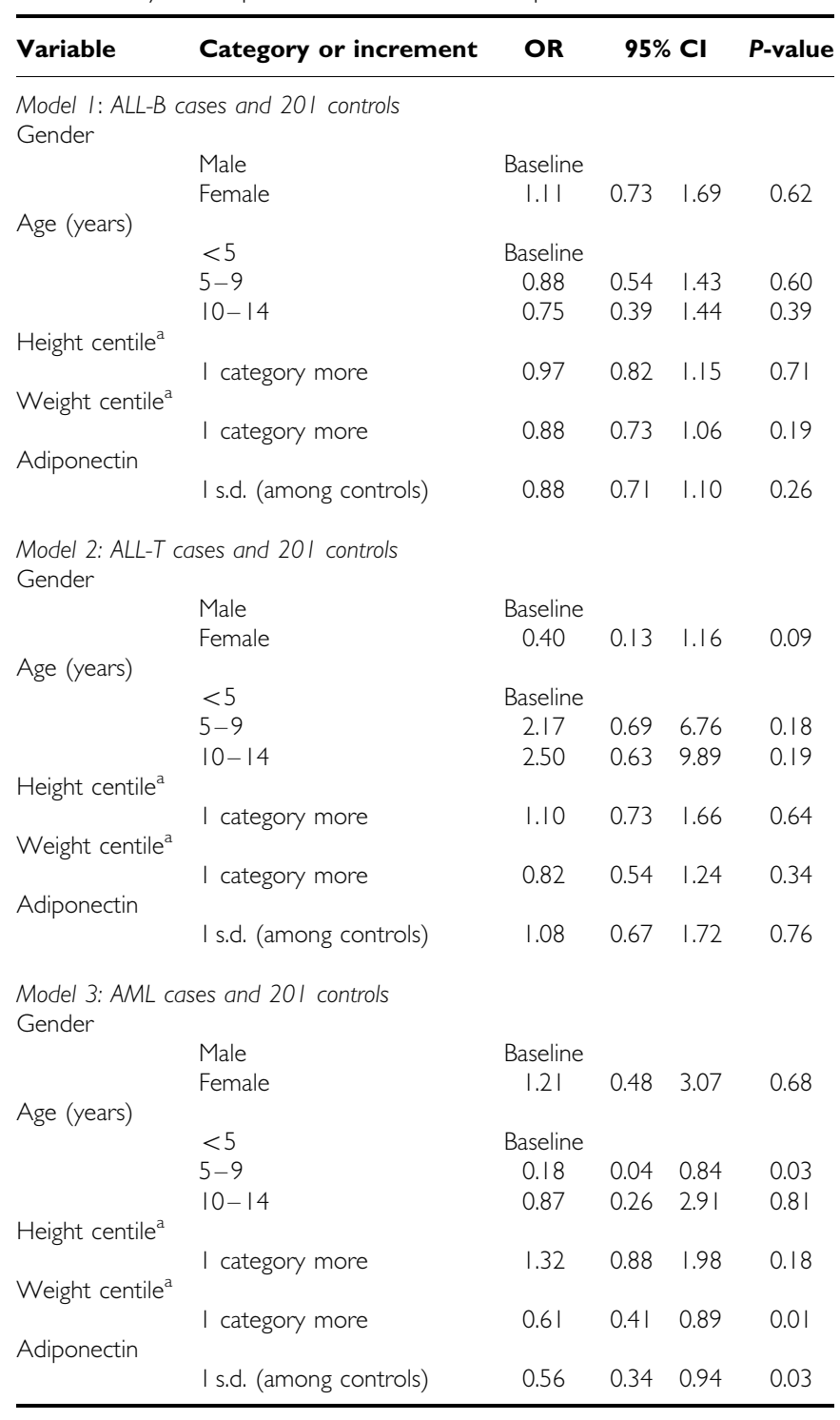

${ }^{a}$ Age- and gender-specific centiles.

there is evidence in these bivariate analyses that levels of adiponectin are lower among children with AML than among apparently healthy controls. In contrast, there is no evidence for an important difference between control children on the one hand and children with ALL-B or ALL-T on the other.

In Table 3, we present multiple logistic regression-derived, adjusted odds ratios (OR) and 95\% confidence intervals (CI) for different types of childhood leukaemia by adiponectin levels, controlling for gender, age as well as for height and weight in agegender-specific centiles. There is no evidence that adiponectin is associated with either ALL-B or ALL-T. With respect to AML, however, adiponectin is inversely, significantly and strongly related to the disease. Weight is also significantly inversely associated with AML. Weight and height in age-gender-specific centiles are not strongly correlated among controls (Spearman's $r=0.35$ ) so that colinearity is not a major problem. Adjusting only for height or only for weight does not materially change the results. Thus, the OR for AML in relation to adiponectin, controlling for gender, age and for height only or weight only are: 0.61 (95\% CI,
$0.37-0.99)$ and 0.55 (95\% CI, 0.34-0.92), respectively. Models, in which body weight and height were introduced as continuous variables (single centile increments), generated similar results (data not shown).

\section{DISCUSSION}

In a nation-wide case-control study in Greece, we found evidence that adiponectin is inversely related to the risk of childhood AML, whereas no such evidence was found with respect to other forms of acute childhood leukaemia. These findings are in line with the working hypothesis generated by a previous report that adiponectin, a hormone that induces apoptosis, inhibits proliferation of myeloid, but not of lymphoid, cell lines (Yokota et al, 2000).

Adiponectin, also called gelatin-binding protein-28, is a 244 amino-acid protein secreted exclusively from white adipose tissue, mainly visceral adipose tissue, to the amount of which it is inversely related (Motoshima et al, 2002). Adiponectin acts principally as an insulin sensitiser; it is inversely associated with parameters of adult obesity and has anti-inflammatory and antiatherogenic effects (Arita et al, 1999; Ouchi et al, 1999; Yokota et al, 2000; Ouchi et al, 2001; Motoshima et al, 2002; Cnop et al, 2003; Gavrila et al, 2003). Four epidemiological studies on adiponectin in relation to cancer have been undertaken among adults and all four have pointed to inverse associations of the hormone with breast cancer (Miyoshi et al 2003; Mantzoros et al 2004b) and endometrial cancer (Petridou et al, 2003; Dal Maso et al, 2004), notably with the postmenopausal forms of the two diseases. Importantly, adiponectin has been reported to induce apoptosis through activation of members of the caspase group of apoptotic enzymes (Brakenhielm et al, 2004) including apoptosis in myelomonocytic leukaemia lines and to predominantly inhibit proliferation of myeloid but not of erythroid or lymphoid cell lines. Treatment of acute myelomonocytic leukaemia lines with adiponectin induces the appearance of subdiploid peaks and oligonucleosomal DNA fragmentation. Moreover, adiponectin regulates inflammatory responses negatively through at least two mechanisms: inhibition of growth of macrophage precursors and suppression of mature macrophage functions (Yokota et al, 2000).

Exclusion of cases and controls from a particular catchments area restricts the study base but should not, by itself, compromise validity. Case ascertainment in our investigation was population based and exclusions were based on administrative or technical reasons that are unlikely to have introduced selection bias. Since blood samples were necessary, we opted for inclusion of hospital controls, which were carefully matched to cases, whereas their admission diagnoses are not known to be related with the principal exposure variable, namely adiponectin. Consequently, there were very few refusals for cooperation among the guardians of both the cases and controls. Adiponectin measurements were blindly performed in a certified laboratory and none of the diagnoses of control subjects have been associated with increased adiponectin levels.

We did not control for components of the insulin-like growth factor (IGF) system; the limited existing evidence for this system refers to ALL rather than AML (Ross et al, 1996; Petridou et al, 2000) and the association between adiponectin and IGF-1 in children is not strong enough to generate considerable confounding (Mantzoros et al, 2004a). Control for height, which is positively and weight, which is inversely associated with adiponectin levels (Mantzoros et al, 2004a), was carried out by using the corresponding age-gender-specific centiles in growth curves among Greek children (Chiotis et al, 2003), thus allowing fine adjustment despite the variable ages of cases and controls ranging between 0 and 14 years of age. We have not controlled for birth weight, both because the evidence for it being associated with childhood leukaemia risk refers mostly to ALL (Hjalgrim et al, 
2003, 2004), and to avoid in the small data set of AML, the consequences of the 'reversal paradox' phenomenon generated when body weight, which is related to birth weight, is found to be a strong predictor of the disease, as was the case in our study (Tu et al, 2005). Children with leukaemia and control children were generally taller and heavier than predicted from the growth curves for Greek children (Chiotis et al, 2003) but this does not affect the ability to control confounding through use of the corresponding age-gender-specific centiles in these scales. MacInnis et al (2005) reviewed among other issues that risk of myeloid leukaemia among adults $27-75$ years old, was positively associated with body mass index whereas lymphoproliferative malignancies and subgroups showed little relationship with body size. We have not been able to document in this data set this association of weight and childhood leukaemia in the univariate analysis. It remains to be investigated whether these divergences are imposed by the small size of our study or differences in the biology between children and older adults. A possible explanation could be that adult height, BMI etc. reflect the life-long effect of the IGF system which also increases risk for leukaemia whereas in children the exposure to the IGF system is not long enough to show positive associations. The strong inverse association of childhood AML with weight that

\section{REFERENCES}

Arita Y, Kihara S, Ouchi N, Takahashi M, Maeda K, Miyagawa J, Hotta K, Shimomura I, Nakamura T, Miyaoka K, Kuriyama H, Nishida M, Yamashita S, Okubo K, Matsubara K, Muraguchi M, Ohmoto Y, Funahashi T, Matsuzawa Y (1999) Paradoxical decrease of an adiposespecific protein, adiponectin, in obesity. Biochem Biophys Res Commun 257: $79-83$

Brakenhielm E, Veitonmaki N, Cao R, Kihara S, Matsuzawa Y, Zhivotovsky B, Funahashi T, Cao Y (2004) Adiponectin-induced antiangiogenesis and antitumor activity involve caspase-mediated endothelial cell apoptosis. Proc Natl Acad Sci USA 101: 2476-2481

Cao R, Wu HL, Veitonmaki N, Linden P, Farnebo J, Shi GY, Cao Y (1999) Suppression of angiogenesis and tumor growth by the inhibitor K1-5 generated by plasmin-mediated proteolysis. Proc Natl Acad Sci USA 96: $5728-5733$

Chiotis D, Tsiftis G, Hatzisymeon M, Maniati-Christidi M, DacouVoutetakis A (2003) Height and weight of children of Hellenic origin aged 0-18 years (2000-2001): comparison with data collected during the period 1978-1979. Ann Clin Pediatr Univ Atheniensis 50: 136-155, (in Greek)

Cnop M, Havel PJ, Utzschneider KM, Carr DB, Sinha MK, Boyko EJ, Retzlaff BM, Knopp RH, Brunzell JD, Kahn SE (2003) Relationship of adiponectin to body fat distribution, insulin sensitivity and plasma lipoproteins: evidence for independent roles of age and sex. Diabetologia 46: $459-469$

Dal Maso L, Augustin LS, Karalis A, Talamini R, Franceschi S, Trichopoulos D, Mantzoros CS, La Vecchia C (2004) Circulating adiponectin and endometrial cancer risk. J Clin Endocrinol Metab 89: 1160-1163

Gavrila A, Chan JL, Yiannakouris N, Kontogianni M, Miller LC, Orlova C, Mantzoros CS (2003) Serum adiponectin levels are inversely associated with overall and central fat distribution but are not directly regulated by acute fasting or leptin administration in humans: cross-sectional and interventional studies. J Clin Endocrinol Metab 88: 4823-4831

Hjalgrim LL, Rostgaard K, Hjalgrim $\mathrm{H}$, Westergaard T, Thomassen $\mathrm{H}$, Forestier E, Gustafsson G, Kristinsson J, Melbye M, Schmiegelow K (2004) Birth weight and risk for childhood leukemia in Denmark, Sweden, Norway, and Iceland. J Natl Cancer Inst 96: 1549-1556

Hjalgrim LL, Westergaard T, Rostgaard K, Schmiegelow K, Melbye M, Hjalgrim H, Engels EA (2003) Birth weight as a risk factor for childhood leukemia: a meta-analysis of 18 epidemiologic studies. Am J Epidemiol 158: $724-735$

MacInnis RJ, English DR, Hopper JL, Giles GG (2005) Body size and composition and the risk of lymphohematopoietic malignancies. J Natl Cancer Inst 97: 1154-1157

Mantzoros C, Petridou E, Alexe DM, Skalkidou A, Dessypris N, Papathoma E, Salvanos H, Shetty G, Gavrila A, Kedikoglou S, Chrousos G, was found in the multivariate analysis of our study has not been previously documented in childhood. Irrespective of whether it is genuine or not, it should not confound the association of adiponectin with AML, given that it is appropriately controlled for.

In conclusion, we have found biologically plausible and empirically strong evidence that among children, adiponectin levels are inversely associated with AML, in contrast to other types of childhood leukaemia. Although adiponectin has generally been considered as a hormone-modulating insulin resistance-related phenomenon in adult life (Arita et al 1999; Stefan et al, 2002; Cnop et al, 2003; Gavrila et al, 2003) the very high levels of this hormone in early life (Mantzoros et al, 2004a) suggest an important role of adiponectin during this period as well. Our in vivo data in combination to the experimental findings by Yokota et al suggest that adiponectin may have a specific role in leukaemia which needs to be explored further in the future. Since there were only 22 children with AML in our study, an unavoidable consequence of the rarity of the disease and the requirement for obtaining blood samples from very young children, our results cannot be considered as conclusive. If confirmed, however, they may provide a unique insight on the pathogenesis of childhood AML and on the early life physiological and pathophysiological role of adiponectin.
Trichopoulos D (2004a) Serum adiponectin concentrations in relation to maternal and perinatal characteristics in newborns. Eur J Endocrinol 151: $741-746$

Mantzoros C, Petridou E, Dessypris N, Chavelas C, Dalamaga M, Alexe DM, Papadiamantis Y, Markopoulos C, Spanos E, Chrousos G, Trichopoulos D (2004b) Adiponectin and breast cancer risk. J Clin Endocrinol Metab 89: $1102-1107$

McNally RJ, Eden TO (2004) An infectious aetiology for childhood acute leukaemia: a review of the evidence. Br J Haematol 127: 243-263

Miyoshi Y, Funahashi T, Kihara S, Taguchi T, Tamaki Y, Matsuzawa Y, Noguchi S (2003) Association of serum adiponectin levels with breast cancer risk. Clin Cancer Res 9: 5699-5704

Motoshima H, Wu X, Sinha MK, Hardy VE, Rosato EL, Barbot DJ, Rosato FE, Goldstein BJ (2002) Differential regulation of adiponectin secretion from cultured human omental and subcutaneous adipocytes: effects of insulin and rosiglitazone. J Clin Endocrinol Metab 87: 5662 - 5667

Ouchi N, Kihara S, Arita Y, Maeda K, Kuriyama H, Okamoto Y, Hotta K, Nishida M, Takahashi M, Nakamura T, Yamashita S, Funahashi T, Matsuzawa Y (1999) Novel modulator for endothelial adhesion molecules: adipocyte-derived plasma protein adiponectin. Circulation 100: $2473-2476$

Ouchi N, Kihara S, Arita Y, Nishida M, Matsuyama A, Okamoto Y, Ishigami M, Kuriyama H, Kishida K, Nishizawa H, Hotta K, Muraguchi M, Ohmoto Y, Yamashita S, Funahashi T, Matsuzawa Y (2001) Adipocytederived plasma protein, adiponectin, suppresses lipid accumulation and class A scavenger receptor expression in human monocyte-derived macrophages. Circulation 103: $1057-1063$

Petridou E, Kassimos D, Kalmanti M, Kosmidis H, Haidas S, Flytzani V, Tong D, Trichopoulos D (1993) Age of exposure to infections and risk of childhood leukaemia. BMJ 307: 774

Petridou E, Mantzoros C, Dessypris N, Koukoulomatis P, Addy C, Voulgaris Z, Chrousos G, Trichopoulos D (2003) Plasma adiponectin concentrations in relations to endometrial cancer: a case-control study in Greece. J Clin Endocrinol Metab 88: $993-997$

Petridou E, Skalkidou A, Dessypris N, Moustaki M, Mantzoros C, Spanos E, Trichopoulos D (2000) Endogenous risk factors for childhood leukaemia in relation to the IGF system (Greece). The Childhood HaematologistsOncologists Group. Cancer Causes Control 11: 765-771

Petridou E, Trichopoulos D (2002) Leukemias. In: Textbook of Cancer Epidemiology, Adami HO, Hunter D, Trichopoulos D (eds). pp 556-572. New York: Oxford University Press

Petridou E, Trichopoulos D, Dessypris N, Flytzani V, Haidas S, Kalmanti M, Koliouskas D, Kosmidis H, Piperopoulou F, Tzortzatou F (1996) Infant leukaemia after in utero exposure to radiation from Chernobyl. Nature 382: $352-353$ 
Randolph TR (2004) Advances in acute lymphoblastic leukemia. Clin Lab Sci 17: $235-245$

Ross JA, Perentesis JP, Robison LL, Davies SM (1996) Big babies and infant leukemia: a role for insulin-like growth factor-1? Cancer Causes Control 7: $553-559$

SAS Institute Inc. (1989) SAS/STAT User's Guide, Version 6, 4th ed. Cary, NC

Stefan N, Vozarova B, Funahashi T, Matsuzawa Y, Weyer C, Lindsay RS, Youngren JF, Havel PJ, Pratley RE, Bogardus C, Tataranni PA (2002) Plasma adiponectin concentration is associated with skeletal muscle insulin receptor tyrosine phosphorylation, and low plasma concentration

\section{Appendix A}

The Childhood Hematology-Oncology Group:

M Moschovi, Hematology-Oncology Unit, First Department of Pediatrics, Athens University Medical School, 'Aghia Sophia' General Children's Hospital, Athens, Greece.

F Athanassiadou- Piperopoulou, 2nd Department of Pediatrics, Aristotle University of Thessaloniki, American Hellenic Educational Progressive Association General Hospital, Thessaloniki, Greece. precedes a decrease in whole-body insulin sensitivity in humans. Diabetes 51: $1884-1888$

Tu YK, West R, Ellison GT, Gilthorpe MS (2005) Why evidence for the feta origins of adult disease might be a statistical artifact: the 'reversal paradox' for the relation between birth weight and blood pressure in later life. Am J Epidemiol 161: 27-32

Yokota T, Oritani K, Takahashi I, Ishikawa J, Matsuyama A, Ouchi N, Kihara S, Funahashi T, Tenner AJ, Tomiyama Y, Matsuzawa Y (2000) Adiponectin, a new member of the family of soluble defense collagens, negatively regulates the growth of myelomonocytic progenitors and the functions of macrophages. Blood 96: 1723-1732

S Polychronopoulou, Department of Pediatric HematologyOncology, 'Aghia Sophia' General Children's Hospital, Athens, Greece.

M Baka, Department of Pediatric Hematology-Oncology, 'Pan.\&Agl. Kyriakou' Children's Hospital, Athens, Greece.

M Kalmanti, Department of Pediatric Hematology-Oncology, University Hospital of Heraklion, Heraklion, Greece. 